\title{
Seagrass habitat loss and fragmentation influence management strategies for a blue crab Callinectes sapidus fishery
}

\author{
Toni Mizerek ${ }^{1}$, Helen M. Regan ${ }^{1,2}$, Kevin A. Hovel ${ }^{1, *}$ \\ ${ }^{1}$ Department of Biology, San Diego State University, 5500 Campanile Drive, San Diego, California 92182-4614, USA \\ ${ }^{2}$ Department of Biology, University of California, 900 University Ave, Riverside, California 92521, USA
}

\begin{abstract}
Marine biodiversity is increasingly threatened by multiple processes, and management strategies therefore must explicitly address the synergistic effects of multiple threats to marine species. The effects of harvesting and habitat degradation may be magnified for many coastal marine fishery species that rely on structurally complex nursery habitats to enhance survival and growth of postlarval and juvenile life history stages. Fishery management strategies that do not account for processes reducing juvenile survival and growth may overestimate the amount of biomass that can be taken; similarly, conservation and restoration strategies for nursery habitats that do not account for variable recruitment may fail. We used the blue crab Callinectes sapidus as a case study to investigate the population-level effects of harvest and seagrass habitat loss and fragmentation. We used available data to parameterize a stochastic stage-based model to test combinations of management strategies, namely reduced harvest rates and introductions of juvenile crabs to nursery habitat. Under a no-harvest scenario, large continuous areas of seagrass supported the largest blue crab populations. However, when harvest rates exceeded $20 \%$, median population abundance was maximized in seascapes composed of smaller, fragmented seagrass patches. Populations in isolated patches of seagrass benefitted more from the introduction of crabs rather than harvest reduction, but the opposite was true for crab populations inhabiting highly connected seagrass seascapes. Management of species that use seagrass beds as nursery habitat must consider the spatial context of multiple threats and their potential synergies to maintain population persistence.
\end{abstract}

KEY WORDS: Habitat fragmentation · Fishing $\cdot$ Blue crab $\cdot$ Callinectes sapidus $\cdot$ Seagrass $\cdot$ Seascape $\cdot$ Reintroduction Resale or republication not permitted without written consent of the publisher

\section{INTRODUCTION}

Conservation and natural resource management practices typically address single threats to populations, communities, and ecosystems, but rarely consider synergistic interactions between threats (Myers et al. 1996, Calkins et al. 1998, Mellink et al. 2002). However, in order to effectively manage populations, it is essential to establish a better understanding of the synergies between threats, particularly in how they influence risks of decline or extinction (Marschall \& Crowder 1996, Myers 1996, Davies et al. 2004, Ewers \& Didham 2005). For many marine organisms, 2 major threats to population persistence are overharvesting and habitat degradation. These threats may be magnified for the large number of coastal marine fishery species that rely on structurally complex nursery habitats to enhance survival and growth of postlarval and juvenile life history stages. For these species and many others, habitats such as subtidal and intertidal seagrass beds, salt marshes, and oyster reefs provide refuge from predation and abundant foraging opportunities, but increasingly are degraded and fragmented (Beck et al. 2001), which threatens to disrupt linkages between early life history stages and recruitment to the fishery (e.g. Irlandi et al. 1995, Hovel \& Lipcius 2002). 
Fishery management strategies that do not account for processes reducing juvenile survival and growth may overestimate the amount of biomass that can be taken; similarly, conservation and restoration strategies for nursery habitats that do not account for variable recruitment may fail.

In this study, we used the blue crab Callinectes sapidus in Chesapeake Bay, USA, as a case study to determine how loss and fragmentation of a key estuarine nursery habitat interacts with harvesting to dictate population persistence. Here, we define fragmentation as the breaking apart of habitat into spatially isolated patches, a process which often accompanies habitat loss (i.e. habitat fragmentation per se: Fahrig 2003). The blue crab forms one of the most valuable singlespecies fisheries along the east coast and gulf coasts of the USA; however, in estuaries such as Chesapeake Bay, blue crab populations are in decline (Fogarty \& Lipcius 2007) at least in part due to excessive fishing pressure (BBCAC 2005). Moreover, eelgrass Zostera marina, the primary nursery habitat for blue crab in Chesapeake Bay (Moody 1994, Perkins-Visser et al. 1996), has declined by $80 \%$ from historical levels due to non-anthropogenic (e.g. storms, digging predators) and anthropogenic (e.g. nutrient loading, sedimentation, propeller scarring) causes (Orth \& Moore 1983).

In Chesapeake Bay, harvest, habitat loss, and habitat fragmentation all may reduce blue crab population size (Hovel \& Lipcius 2001, Sharov et al. 2003, Fogarty \& Lipcius 2007), but studies evaluating these threats, and management options to overcome them, have not considered their potential interactions. Moreover, the effects of seagrass habitat fragmentation and loss on blue crabs may be complex. Whereas loss of seagrass reduces the availability of refuge and foraging habitat, and seagrass patchiness increases the risks associated with movement among patches (Micheli \& Peterson 1999), relative survival of tethered juvenile blue crabs is higher in small isolated patches than in larger continuous patches. This likely is due to reduced predator abundance in sparse, highly fragmented seagrass seascapes (Hovel \& Lipcius 2001). Additionally, the effects of seagrass loss and fragmentation on blue crab survival and abundance vary ontogenetically, seasonally, and with crab density (Hovel \& Lipcius 2002).

Our goal in this study was to determine how the loss and fragmentation of seagrass habitat may influence the success of different blue crab management scenarios (reductions in harvest and stock enhancement; blue crabs are hatchery-reared and released into the bay as a stock enhancement strategy). To do this, we constructed simulated seascapes consisting of seagrass patches embedded within a matrix of unvegetated sediment and used a stage-based matrix model to subject crabs within seagrass habitat to a variety of harvest and stock enhancement scenarios. Although blue crabs settle and mature within a variety of habitat types (Fogarty \& Lipcius 2007), we chose to use a patchmatrix seascape consisting only of seagrass (habitat) and unvegetated sediment (non-habitat) to explicitly model the effects of fragmentation and loss of the primary blue crab nursery habitat in Chesapeake Bay, for which information is available on survival and abundance. Our model addressed 2 primary questions: (1) What combination of seascape configuration and harvest rate results in the largest population of blue crabs over the long-term (50 yr)? (2) Under what combination of seascape configuration and harvest rate is seeding of juvenile blue crabs most effective as promoting persistence of blue crab populations?

\section{MATERIALS AND METHODS}

Population models. We modified an existing deterministic stage-based model for blue crab populations in Chesapeake Bay (Miller 2001) to include spatial heterogeneity, stochasticity, density dependence, and habitat-dependent survival rates for juvenile stages (see Miller 2001 for full description of blue crab life history and justification for model structure). Environmental variability was represented as a probability distribution for each survival rate, transition rate (i.e. growth rate from smaller to larger stages), and fecundity in the matrix model. We constructed the stagebased stochastic models in the software platform RAMAS Metapop ${ }^{\circledR}$ (Akçakaya \& Root 1998) to simulate the population dynamics under a range of harvest, seeding/stocking, and seagrass loss and fragmentation scenarios. This platform propagates variability across parameters via Monte Carlo simulations. We explain below how each model parameter was estimated, how environmental variability is represented for each parameter, the type of density dependence modeled, and how spatial heterogeneity and management scenarios were implemented in the models.

Selection of seascape types. We first identified 4 seascape types (henceforth simply 'seascapes') based on a series of aerial photographs taken of the lower York River in Chesapeake Bay, an area in which wave and current scouring, digging predators, and boating and fishing practices create a mosaic of seagrass seascapes that vary from undisturbed, continuous seagrass cover to small, isolated seagrass patches (Hovel \& Lipcius 2001). Four seascapes were selected from the aerial photographs to represent the full range of average seagrass patch sizes and isolation between patches: continuous (connected) seagrass, large patches of seagrass isolated from one another, small patches close to one another, and very small isolated patches of seagrass 

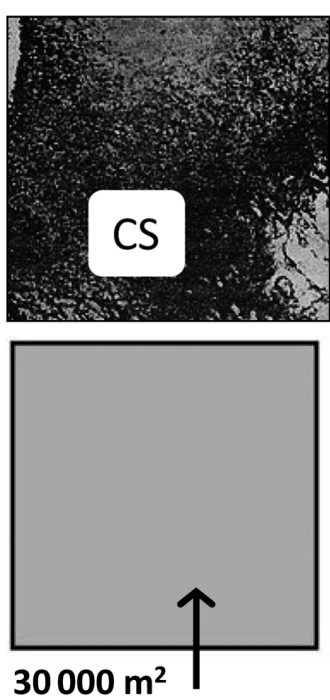
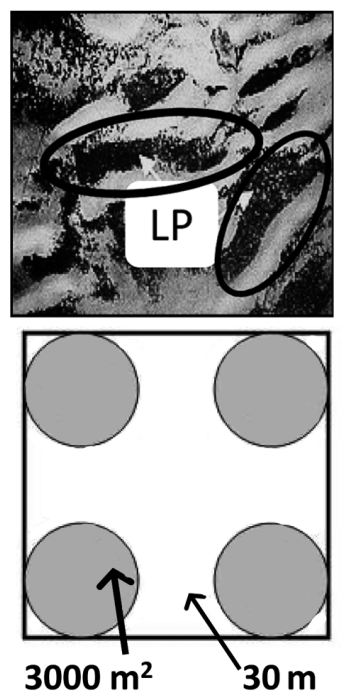
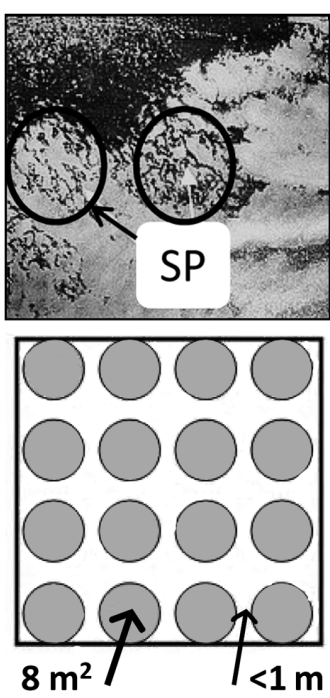
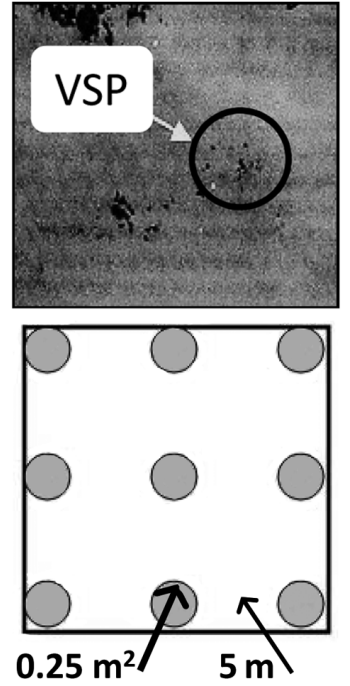

Fig. 1. Zostera marina. Aerial photographs of eelgrass beds (dark patches) in the lower York River, Chesapeake Bay (upper panels), and visual schematic of the layout of seagrass beds in each model representing different fragmentation types (lower panels). From left to right: continuous seagrass (CS), large isolated patches (LP), small close patches (SP), and very small isolated patches (VSP). The area of the box is held constant $\left(30000 \mathrm{~m}^{2}\right)$, and the amount of seagrass varies in each model based on patch size and isolation by unvegetated sediment. Size of seagrass beds not to scale. Color photographs and detailed habitat descriptions are provided in Hovel \& Lipcius (2001)

(Fig. 1). These 4 seascapes provide the spatial underpinnings for 4 separate population models. The models differ in 2 key ways: (1) the number of large and adult blue crabs supported by the available seagrass habitat, and (2) the survival rates for small crabs, as indicated by field data (Hovel \& Lipcius 2002). The link between the seascapes and the population model is provided by these 2 components (see below for more detail).

The average size of the patches, as well as the area of unvegetated sediment between patches, varied across the 4 seascapes (Fig. 1, Table 1; refer to Hovel \& Lipcius 2001 for aerial maps). For consistency, each seascape was set within a $30000 \mathrm{~m}^{2}$ spatial context (i.e. for each scenario the average sized patch was repeated, with the average distance between patches, to fill a total area of $30000 \mathrm{~m}^{2}$; Fig. 1). This spatial scale was chosen (1) to isolate seascapes for exploration of spatial structure on population dynamics, and (2) to investigate management actions which occur on localized scales. Continuous patches average 3 ha in area, hence the other seascapes were scaled to match this within their respective spatial context (Fig. 1). These seascapes were used in separate models representing unique scenarios where the total amount and configuration of seagrass habitat differed in each.

Stage-based matrix model. The life history of this species is best described by 4 stages which are defined according to carapace width (CW): megalopae, small age 1 crabs, large age 1 crabs, and adults (see Miller 2001 for CW). In this model, individuals transition between stages across 2 seasons annually, summer and winter (Fig. 2), according to the equation:

$$
\left[\begin{array}{c}
N_{1}(t+1) \\
N_{2}(t+1) \\
N_{3}(t+1) \\
N_{4}(t+1)
\end{array}\right]=\mathbf{A}_{\text {summer }} \times \mathbf{A}_{\text {winter }} \times\left[\begin{array}{c}
N_{1}(t) \\
N_{2}(t) \\
N_{3}(t) \\
N_{4}(t)
\end{array}\right]
$$

where $N_{i}(t)$ for $i=1, \ldots, 4$ is the number of megalopae, small age 1 crabs, large age 1 crabs, and adults, respectively, in year $t$. The annual time step begins with the winter season (December to May) and ends at the conclusion of the summer season (June to November). $\mathbf{A}_{\text {summer }}$ and $\mathbf{A}_{\text {winter }}$ are the transitions in the winter and summer, represented by the following matrices:

$$
\begin{aligned}
\mathbf{A}_{\text {winter }} & =\left[\begin{array}{cccc}
0 & 0 & a w_{13} & a w_{14} \\
a w_{21} & 0 & 0 & 0 \\
a w_{31} & 0 & 0 & 0 \\
0 & a w_{42} & a w_{43} & a w_{44}
\end{array}\right] \\
\mathbf{A}_{\text {summer }} & =\left[\begin{array}{cccc}
a S_{11} & 0 & 0 & 0 \\
0 & a S_{22} & 0 & 0 \\
0 & a s_{32} & a S_{33} & 0 \\
0 & 0 & 0 & a s_{44}
\end{array}\right]
\end{aligned}
$$

where $a w_{i j}, a s_{i j}$ are the winter and summer transition rates, respectively, from stage $j$ to stage $i$.

All parameters were either derived from functions of 2 fundamental parameters, number of female offspring $(B)$ and natural mortality $(M)$ (Miller 2001 and Table 1), or based on direct observational data (Hovel \& Lipcius 2002; Table 1, Fig. 3). To estimate the annual number of female offspring $(B)$, we assumed a 50:50 sex ratio and 
Table 1. Definition and estimated value of blue crab model parameters (modified from Miller 2001). Estimated values are either based on Hovel $\&$ Lipcius (2002) or calculated as functions of the fundamental parameters $M$ and $B$ as indicated below. Values are means $\pm 1 \mathrm{SD}$ (parentheses) or range (brackets). NA: not applicable

\begin{tabular}{|c|c|c|}
\hline Symbol & Parameter & Value \\
\hline$M / 2$ & Seasonal natural mortality & $0.274(0.137)$ \\
\hline$B$ & Maternity & $1.6 \times 10^{6}\left[7.5 \times 10^{5}, 8.0 \times 10^{6}\right]$ \\
\hline$a s_{11}$ & Zoea/megalopae survival & $1.2 \times 10^{-5}\left(6 \times 10^{-6}\right)$ \\
\hline$a s_{22}{ }^{a}$ & $\begin{array}{l}\text { Summer megalopae to } \\
\text { overwintering juvenile } \\
\text { transition rate }\end{array}$ & $\begin{array}{l}\text { Dependent on habitat } \\
\text { fragmentation (see Fig. 3) }\end{array}$ \\
\hline$a s_{32}{ }^{\mathrm{a}}$ & $\begin{array}{l}\text { Summer small age } 1 \text { to } \\
\text { overwintering large age } \\
1 \text { transition rate }\end{array}$ & $\begin{array}{l}\text { Dependent on habitat } \\
\text { fragmentation type } \\
\text { (see Fig. 3) }\end{array}$ \\
\hline$a S_{33}$ & $\mathrm{e}^{-M / 2}$ & $0.760(0.094)$ \\
\hline$a s_{44}$ & $\mathrm{e}^{-M / 2}$ & $0.760(0.094)$ \\
\hline$a w_{13}$ & $0.66 \times B \mathrm{e}^{-M / 2}$ & 802909 (1000000) \\
\hline$a w_{14}$ & $B \mathrm{e}^{-M / 2}$ & $1216528(1414214)$ \\
\hline$a w_{21}{ }^{\mathrm{a}}$ & $\begin{array}{l}\text { Overwintering juvenile to } \\
\text { summer small age } 1 \\
\text { transition rate }\end{array}$ & $\begin{array}{l}\text { Dependent on habitat } \\
\text { fragmentation (see Fig. 3) }\end{array}$ \\
\hline$a w_{31}{ }^{\mathrm{a}}$ & $\begin{array}{l}\text { Overwintering juvenile to } \\
\text { summer large age } 1 \\
\text { transition rate }\end{array}$ & $\begin{array}{l}\text { Dependent on habitat } \\
\text { fragmentation (see Fig. 3) }\end{array}$ \\
\hline$a w_{42}$ & $\mathrm{e}^{-M / 2}$ & $0.760(0.094)$ \\
\hline$a w_{43}$ & $\mathrm{e}^{-M / 2}$ & $0.760(0.094)$ \\
\hline$a w_{44}$ & $\mathrm{e}^{-M / 2}$ & $0.760(0.094)$ \\
\hline$K_{\mathrm{CS}}{ }^{\mathrm{b}}$ & $\begin{array}{l}\text { Adult carrying capacity in } \\
\text { continuous patch } \\
\left(\text { across } 30000 \mathrm{~m}^{2}\right)\end{array}$ & 27530 \\
\hline$K_{\mathrm{LP}}$ & $\begin{array}{l}\text { Adult carrying capacity in } \\
\text { habitat with large isolated } \\
\text { patches (across } 30000 \mathrm{~m}^{2} \text { ) }\end{array}$ & 4730 \\
\hline$K_{\mathrm{SP}}$ & $\begin{array}{l}\text { Adult carrying capacity, } \\
\text { per patch, in small close } \\
\text { patches (across } 30000 \mathrm{~m}^{2} \text { ) }\end{array}$ & 19880 \\
\hline$K_{\mathrm{VSP}}$ & $\begin{array}{l}\text { Adult carrying capacity, } \\
\text { per patch, in very small } \\
\text { isolated patches } \\
\left(\text { across } 30000 \mathrm{~m}^{2}\right)\end{array}$ & 5100 \\
\hline$S_{\mathrm{CS}}, D_{\mathrm{CS}}$ & $\begin{array}{l}\text { Average size }\left(\mathrm{m}^{2}\right) \text { of } \\
\text { individual patches \& } \\
\text { average distance }(\mathrm{m}) \\
\text { between patches for } \\
\text { continuous patch }\end{array}$ & 30000; NA \\
\hline$S_{\mathrm{LP}}, D_{\mathrm{LP}}$ & $\begin{array}{l}\text { Average size }\left(\mathrm{m}^{2}\right) \text { of } \\
\text { individual patches \& } \\
\text { average distance }(\mathrm{m}) \\
\text { between patches for } \\
\text { large isolated patches }\end{array}$ & $3000 ; 30$ \\
\hline$S_{\mathrm{SP}}, D_{\mathrm{SP}}$ & $\begin{array}{l}\text { Average size }\left(\mathrm{m}^{2}\right) \text { of } \\
\text { individual patches \& } \\
\text { average distance }(\mathrm{m}) \\
\text { between patches for } \\
\text { small close patches }\end{array}$ & $8 ;<1$ \\
\hline$S_{\mathrm{VSP}}, D_{\mathrm{VSI}}$ & $\begin{array}{l}\text { Average size }\left(\mathrm{m}^{2}\right) \text { of } \\
\text { individual patches \& } \\
\text { average distance }(\mathrm{m}) \\
\text { between patches for very } \\
\text { small isolated patches }\end{array}$ & $0.25 ; 5$ \\
\hline \multicolumn{3}{|c|}{$\begin{array}{l}\text { a A perturbation of } 10 \% \text { in } a s_{21}, a S_{31}, a S_{22} \text {, and } a S_{32} \text { simultaneously } \\
\text { resulted in a perturbation of } 18 \% \text { in median population threshold } \\
\text { b A perturbation of } 10 \% \text { in } K_{\mathrm{CS}} \text { alone resulted in a perturbation of } \\
12 \% \text { in median population threshold }\end{array}$} \\
\hline
\end{tabular}

halved the number of offspring for an average size adult female blue crab (3.2 million; Prager et al. 1990) to yield 1.6 million female offspring per average size female adult per year. Since estimates of the standard deviation were unavailable, the published range of values for number of offspring was used to establish standard deviations for parameters expressed as functions of $B$ (SERC 2006; Table 1). Since the annual census (in the model) is taken just before the birth pulse, it is necessary to include a mortality factor for offspring from birth to the census. We therefore multiplied the average value of $B$ by a mortality factor to convert maternity into fecundity (Table 1). Fecundity of large age 1 crabs is reported as $\sim 66 \%$ of adult fecundity (Miller 2001). Due to the considerable uncertainty in the birth rate, we performed a sensitivity analysis on this parameter to determine the impact of changes in this parameter on model output (see 'Materials and methods - Sensitivity analysis' below).

Juvenile and adult survival rates are functions of annual natural mortality, which is based on maximum life expectancy of individuals. The Chesapeake Bay blue crab maximum age $\left(t_{\max }\right)$ is postulated to be 8 yr (Rugolo et al. 1998), and this was used to predict a natural mortality rate calculated as $\ln (M)=1.44-$ $0.982 \times \ln \left(t_{\text {max }}\right)$ (Hewitt \& Hoenig 2005$)$ resulting in $M=0.548$. Natural mortality is represented in the seasonal submatrices; therefore, the estimated rate for a 6 mo period is 0.274 (= $M / 2)$. The uncertainty and variability is represented by a lognormal probability distribution for $M$ with a mean of 0.274 and a conservative $50 \%$ coefficient of variation.

Two population-level factors varied between each of the seascapes: seasonal survival rates of small age 1 crabs, and number of subadult and adult crabs for each seagrass habitat seascape. In the summer and winter seasons of 1998, Hovel \& Lipcius (2002) used tethering experiments to assess relative differences in survival rates of small age 1 blue crabs across 4 seagrass fragmentation levels in Chesapeake Bay. These average survival rates of juveniles for each seascape (Fig. 3) were then increased by $10 \%$ to partially account for a relative effect of tethering (Pile et al. 1996). These were then partitioned into transition rates to summering small age $1\left(a w_{21}\right)$ and summering large age 1 crabs $\left(a w_{31}\right)$ for overwintering juveniles, and overwintering small age $1\left(a w_{22}\right)$ and overwintering large age 1 


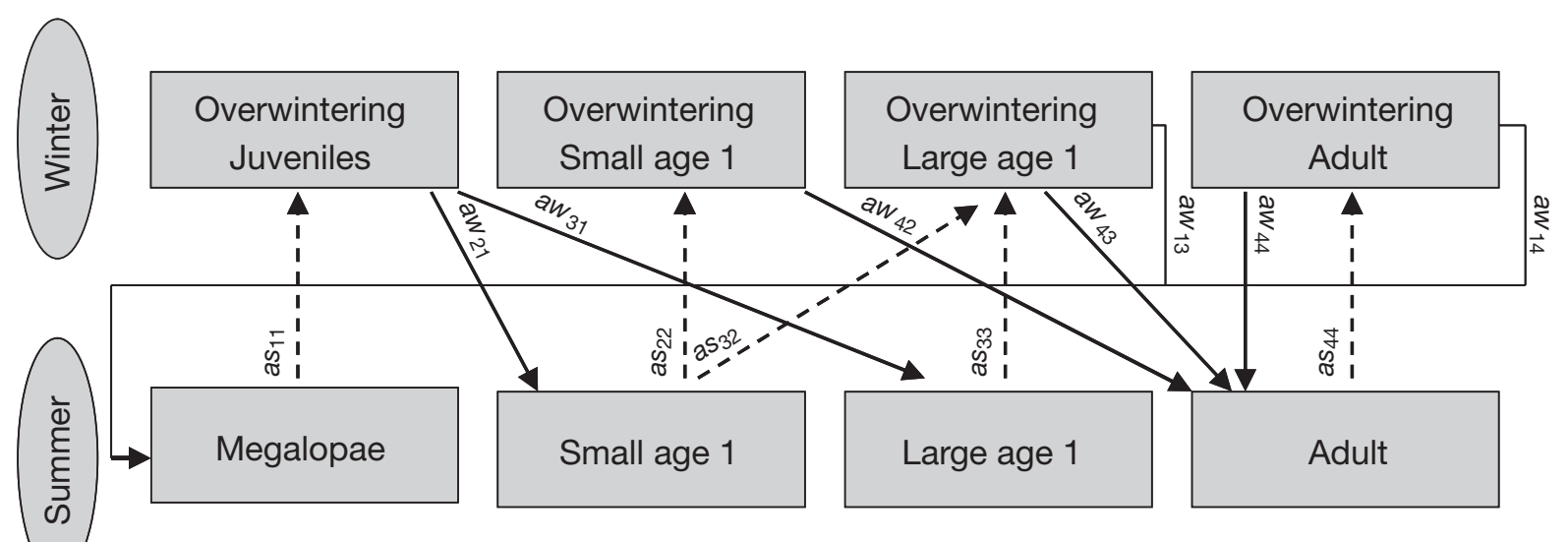

Fig. 2. Callinectes sapidus. Life history diagram (adapted from Miller 2001) of blue crabs, representing summer transitions (dashed arrows) and winter transitions (solid arrows). Potential stage transitions are labeled with transition probabilities (see Table 1 for definitions)

crabs $\left(a w_{32}\right)$ for summering juveniles, at a ratio of 85:15 (based on Rothschild et al. 1988). Due to uncertainty and unknown temporal variability in these estimates, a lognormal distribution with a coefficient of variation of $50 \%$ was used for this transition probability. This level of variability was later perturbed in a sensitivity analysis to ascertain its importance in overall management rankings.

Of the total number of eggs produced and released by blue crabs, larval survival through the zoeal and megalopal stage is low, primarily because of predation and variable resource availability in the pelagic environment. The mean survival rate through this initial

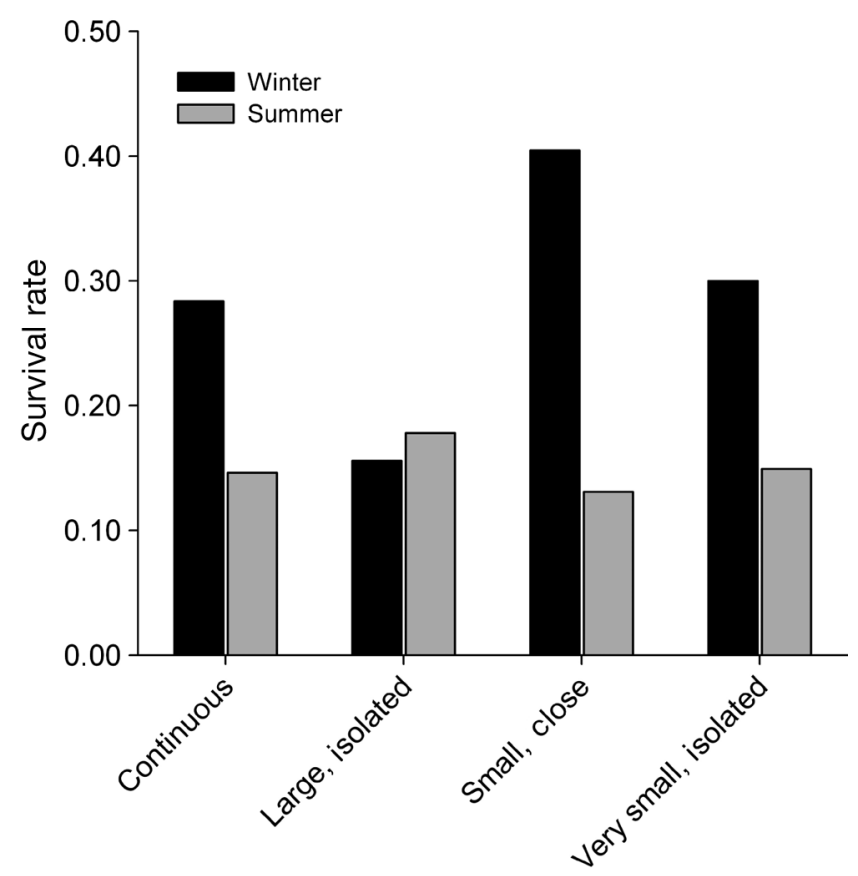

Fig. 3. Callinectes sapidus. Winter and summer small age 1 blue crab survival rates per habitat fragmentation type (Hovel \& Lipcius 2002, K. A. Hovel unpubl. data) stage of the blue crab life cycle was assumed to be $\left(1.2 \times 10^{-5}\right)$ to ensure a positive deterministic intrinsic growth rate for all seascapes. Again, a 50\% coefficient of variation with a lognormal distribution was assumed because of the inherent variability and uncertainty. For parameters calculated as functions of the independent variables $M$ and $B$ in Table 1, means and standard deviations were estimated from the distributions resulting from stratified sampling, and subsequent convolution, of the respective functions of $M$ and $B$. Lognormal distributions were then assumed for these parameters with the estimated means and standard deviations.

Density dependence. Hovel \& Lipcius (2001) observed that the number of blue crabs $50 \mathrm{~mm} \mathrm{CW}$ or larger depended strongly on the seascape and amount of habitat present. We incorporated this into the model by assuming the Beverton-Holt function for blue crabs $50 \mathrm{~mm} \mathrm{CW}$ or larger (i.e. crabs in the large age 1 and adult stages). The Beverton-Holt function models density dependence (i.e. a decline in population growth rate as population size increases) as a function of carrying capacity and was originally developed to include contest competition for fisheries models (Beverton \& Holt 1957). In the absence of information about the smaller stages, carrying capacities were not applied to megalopae, juvenile, or small age 1 crabs. Carrying capacities for each seascape were set based on the average number of blue crabs of this size found during trawl surveys in each seascape (Hovel \& Lipcius 2001) and by restricting crabs to seagrass habitat in the model. These were then scaled to correspond to the dimensions of the total simulated spatial area considered for each seascape $\left(30000 \mathrm{~m}^{2}\right.$ for each type; Table 1). The trawling surveys showed that as the size of seagrass patches increased so did the numbers of subadult and adult blue crabs present across patchy areas. While subadult and adult blue crabs are found in a much larger array of habitats, including unvege- 
tated areas, the trawling data collected by Hovel \& Lipcius (2001) indicate that some dependence of adult and subadult stages on the amount of nursery habitat is plausible. While the carrying capacities applied here underestimate the actual carrying capacity possible, they provide an empirically-based consistent lower bound that can be used across all scenarios for ranking and comparing outcomes of management and seascape. The seascape characteristics are defined by the carrying capacity of each seascape and the juvenile survival rates (Figs. $1 \& 3$, Table 1). In this model, individuals do not occupy coordinates in space; rather, the population is aggregated and its dynamics within a seascape are governed by the demographic and habitat parameters for that particular scenario. In order to restrict focus to population dynamics in the seascape without the potentially confounding effects of alternative spatial structures, each seascape is modeled separately and in isolation of the other seascapes.

Management strategies. To assess the impacts of harvesting in various habitats, we applied the same fishing pressure to populations in each of the seascapes. A constant adult harvest rate (i.e. a constant proportion of the adult stock), which is currently believed to be optimal for maximum sustainable yield, was applied to each model at the end of each time step. Current management of the Chesapeake Bay blue crab stock recommends a fishing mortality rate threshold of 0.7 , which preserves a minimum of $20 \%$ of the spawning potential of an unfished stock (CBSAC 2005, Miller et al. 2005). This rate corresponds to 50\% annual removal. Adult harvest rates of 30,20 , and $10 \%$ were also tested to examine the effect of a range of reduced fishing mortality rates on population persistence. For all scenarios, harvest or seeding/stocking of juveniles started in Year 25 of the model simulations to allow populations to initialize and average population dynamics to stabilize before removal of individuals.

To determine how the interaction of introductions, harvesting, and habitat fragmentation impact blue crab population dynamics, we simulated annual introductions of 100, 200, 400, and 800 small age 1 blue crabs from Years 25 to 50 for each seascape in conjunction with constant harvest rates of 20,30 , and $50 \%$.

Sensitivity analysis. We performed a sensitivity analysis on the population model in the absence of management actions. The analysis was performed only for the continuous seagrass seascape, but the results apply across all seascapes because only carrying capacities and small age 1 blue crab survival rates varied among seascapes. Each of the parameters in the model, including coefficients of variation, and the fundamental parameters $M$ and $B$, were perturbed by $\pm 10 \%$ (see Table 1 for the full list of parameters, all of which were individually perturbed in separate sensitivity analyses). Sensitivity was defined as the relative difference in median population threshold before and after the perturbation. The model was deemed sensitive to a parameter if the sensitivity was greater than the initial extent of the perturbation $(10 \%)$. The sensitivity of model results to the type of density dependence was tested by changing density dependence to a Ricker function (i.e. scramble competition) and exponential growth with a ceiling. Selected combinations of parameters were also perturbed simultaneously to measure the effect of compounding uncertainty in multiple parameters.

Simulations. The initial abundance for model simulations for each seascape was 35000 total individuals across all stages. Our aim was to compare the effects of fragmentation and habitat loss on population dynamics without the confounding effects of differences in initial population size. We therefore assumed equal total initial population size across all seascapes. The total abundance was then distributed across stages according to the stable stage distribution for the relevant seascape. Stochasticity was incorporated through Monte Carlo simulations for 1000 replications over a $50 \mathrm{yr}$ period to account for natural variation in both the environment and the demographics of the population.

The median of the final population sizes (i.e. population abundance in Year 50) across the 50 yr trajectories ( $n=1000$ ) was used to rank population persistence across each harvest, introduction, and seascape scenario tested (Burgman et al. 1993, Akçakaya et al. 1999). Hereafter this metric is referred to as the median population threshold $;$ it is a measure of the central tendency of the population abundance after the model is run for 50 annual time steps.

\section{RESULTS}

\section{Interactive effects of seascape and harvest rate on blue crab populations}

In the absence of harvest, the largest median population threshold was supported in continuous seagrass (Fig. 4). Although a higher harvest rate reduced the median population threshold across all seascapes, the optimal seascape configuration for blue crabs shifted from continuous seagrass to patchy seagrass as a higher fraction of the population was harvested. Continuous seagrass still supported the largest median population threshold with harvest rates set at $10 \%$, but under harvest rates of $20 \%$ and greater, there was a shift in optimal habitat from continuous seagrass to small close patches of seagrass. Population declines due to increasing harvest were steepest in continuous 


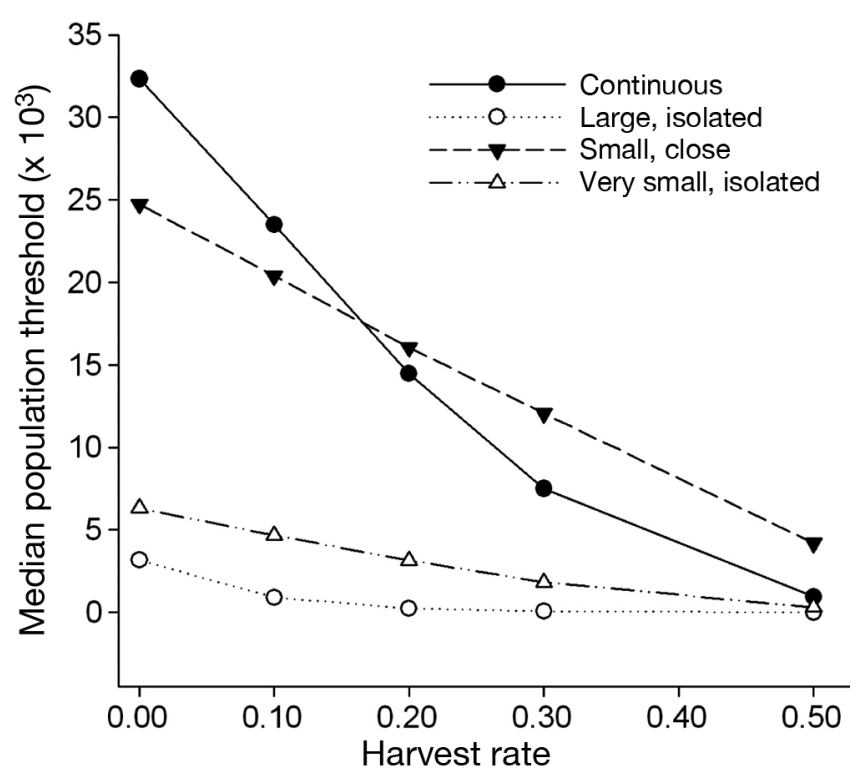

Fig. 4. Callinectes sapidus. Median population threshold at the end of $50 \mathrm{yr}$ under a range of harvest rates across the 4 seagrass fragmentation types

seagrass, followed by seascapes composed of small, close seagrass patches. While the population in large isolated patches had the least dramatic decline with increased harvest rates, it was nearly extirpated with a harvest rate of $50 \%$.

\section{Effects of stock enhancement on blue crab populations}

Under a $50 \%$ harvest rate, introductions caused the greatest absolute population increase in small close patches, whereas the greatest relative increase occurred in large isolated patches (Fig. 5). This trend reversed when the lowest absolute and relative increases were considered: large isolated patches displayed the lowest absolute population increase, whereas the lowest relative increase occurred in small close patches.

A general distinction emerged between the relative effects of harvest reduction versus introductions for large, isolated patches and continuous seagrass (Fig. 6). The smallest relative increase in median population threshold with introductions occurred in a seascape of continuous seagrass (a similar pattern emerged for the small close patches; results not shown). In this seascape, reductions in harvest rate from 50 to $30 \%$ and $20 \%$ had greater impacts on population persistence than blue crab introductions (Fig. 5). The maximum number of introductions tested here (i.e. $800 \mathrm{yr}^{-1}$ ) never increased the median population threshold more than when reducing the harvest rate alone. Furthermore, the similar slopes of the response graphs for each harvest level indicate that the effect of introduc-

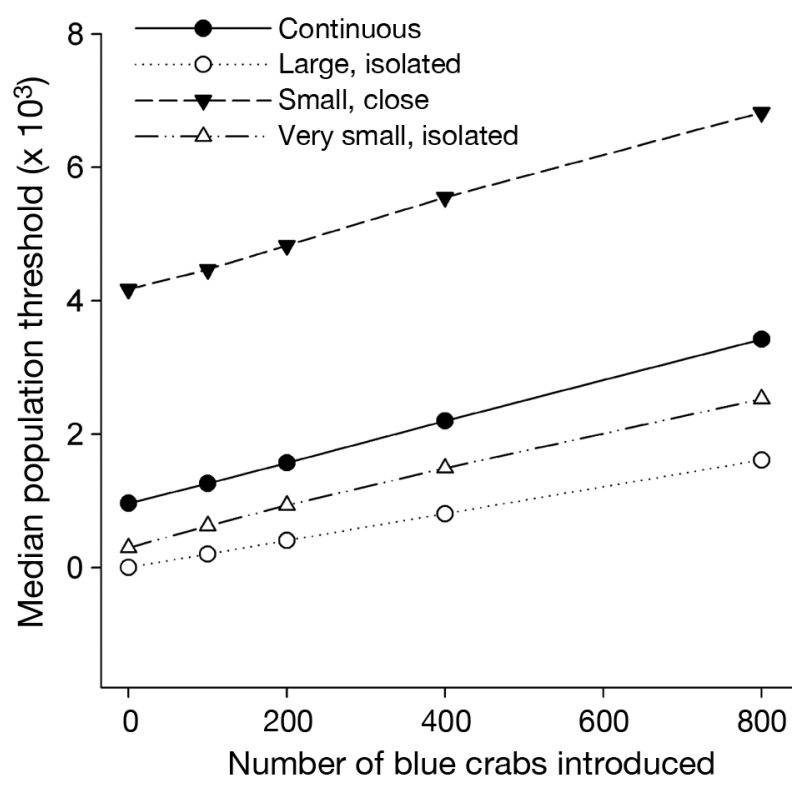

Fig. 5. Callinectes sapidus. Median population threshold for small age 1 blue crabs introduced annually within each of the seagrass fragmentation types under a $50 \%$ annual harvest rate

tions on median population threshold is almost identical (Fig. 6).

In a seascape of large, isolated patches of seagrass, the relative effects of introductions and reduced harvest were reversed (a similar pattern emerged for the very small isolated patches; results not shown). The relative increase in median population threshold with introductions outweighed that of harvest reduction. Hence, the benefit of supplementing populations in a seascape of isolated seagrass patches was greater than the benefit of reducing the harvest rate alone. The median population threshold with 400 introductions under a $50 \%$ harvest rate in large, isolated patches of seagrass was greater than that with no introductions and a harvest rate reduced to $20 \%$ (Fig. 6).

\section{Sensitivity analysis}

The greatest change in model output occurred with a simultaneous increase in the summer and winter survival rates of juvenile blue crabs (a relative change of $18 \%$ in model output with $10 \%$ changes in both parameters). This indicates that if these parameters are both in error then model results may change by a disproportionate amount to the extent of the error. It also suggests that if both seasonal survival rates of this blue crab stage were to increase, there may be a significant impact on the population growth. Adjustments to the carrying capacity and a change from contest density dependence to exponential growth with a ceiling resulted in relative changes in model output of up to 


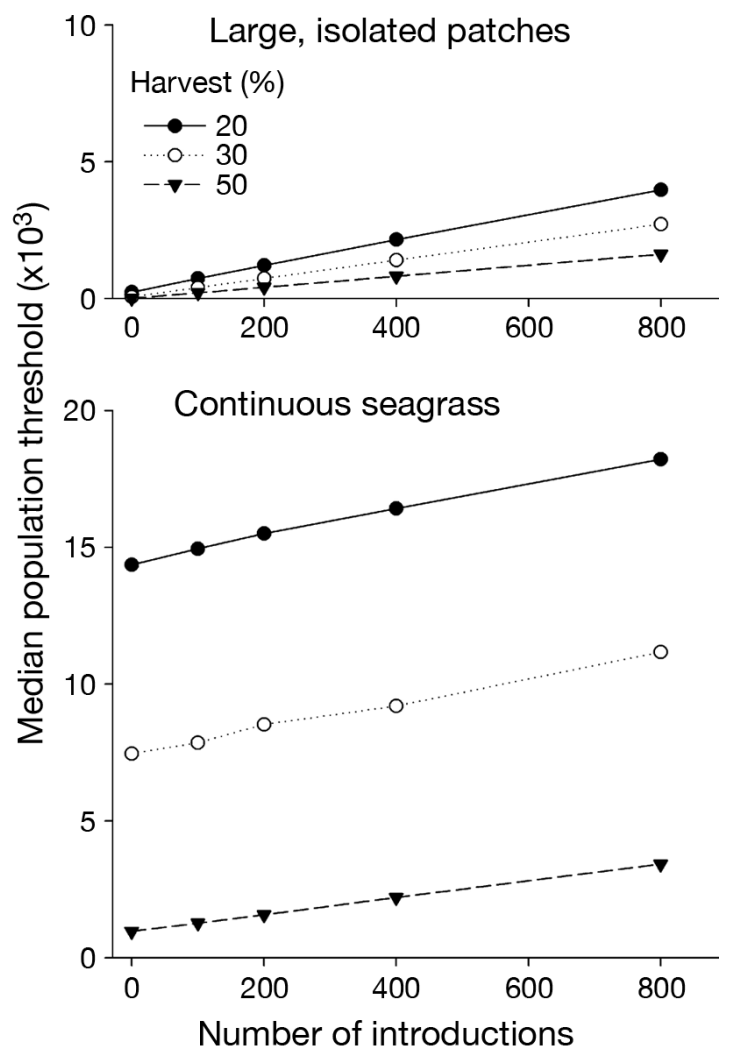

Fig. 6. Callinectes sapidus. Median population threshold under a range of harvest rates $(20,30,50 \%)$ and number of small age 1 blue crabs introduced $(0,100,200,400,800)$ within seascapes of connected seagrass (based on the continuous seagrass habitat) and a seascape of isolated patches of seagrass (based on large isolated patches)

$12 \%$. Perturbations of $10 \%$ to all other parameters, including coefficients of variation for all parameters, resulted in relative changes to model output of less than $10 \%$, indicating that the model results are fairly insensitive to parameter errors of this magnitude.

\section{DISCUSSION}

Many marine fishery species use shallow coastal habitats such as seagrasses, oyster reefs, and salt marshes as refuge and foraging areas, all of which commonly are degraded and fragmented. Habitat loss, habitat fragmentation, and overfishing therefore may synergistically threaten a variety of fishery species such as blue crabs that have high economic, ecological, and cultural significance (Paolisso 2002). Our model suggests that the influence of seagrass seascape structure on blue crab persistence varies with harvest rate. In the absence of harvest, continuous seagrass seascapes are optimal habitat for blue crab population persistence, because even though high predator abundance re- duces juvenile blue crab survival, this habitat supports the largest number of crabs. Seascapes composed of small seagrass patches that are isolated by short distances also promoted population persistence in the absence of harvest. Adults may be less likely to congregate in these patches of seagrass due to fewer resources, or more visibility to predators, and young crabs can temporarily leave the safety of a patch to move the short distances across unvegetated sediment to nearby patches without a significant increase in mortality (Moksnes et al. 1997). Both of these habitat configurations accommodated higher abundances than the 2 isolated patch configurations.

When harvest rates greater than $10 \%$ were implemented, population persistence was maximized in seascapes composed of small close patches of seagrass rather than continuous seagrass. Even when $50 \%$ of the adult population is harvested annually, the population abundance increased more quickly in small close patches than in the other seascapes due to high survival rates for small age 1 crabs. Thus it is possible that this survival rate is sufficient to sustain the population under a $50 \%$ harvest rate.

These results have implications for the fishery. At the conclusion of the $50 \mathrm{yr}$ time period, the total number of crabs harvested was greatest in small close patches of seagrass even though continuous seagrass can accommodate a larger number of adult crabs. The amount harvested decreased annually in the continuous habitat because the population could not recover sufficiently before the next harvest event. The larger average growth rate allows the population in small close patches to recover more quickly after a harvest. Therefore, under a $50 \%$ harvest rate, the amount harvested annually in a habitat of small close patches remains fairly constant.

There was a significant increase in the median population threshold when harvest rates were reduced for connected patches of seagrass. A reduction in the harvest rate in connected habitats resulted in a much higher number of adults than for isolated patches. Continuous seagrass promoted the highest abundance for a harvest rate of $10 \%$ because so few adults are removed that the population can quickly increase to pre-harvest numbers. However, it is unlikely that this low harvest limit would be implemented (Paolisso 2002, Rosenberg 2003). Reducing the harvest rate below $50 \%$ for populations in isolated patches does not result in a large increase in median population threshold simply because the population begins at a small size when harvesting begins. It is clear that successful management of the population by solely reducing the harvest rate depends on the habitat conditions and the number of adult crabs present. The interesting issue here is that the seascapes with the highest proportional 
cover of seagrass (and therefore the highest carrying capacities) are not necessarily optimal for crab survival. Understanding the apparent trade-off between patchiness and juvenile survival rate appears crucial in managing this fishery across a heterogeneous seascape. Further research to determine the effectiveness of increasing small age 1 crab survival could also promote recovery after harvest.

The extent to which introductions improve population persistence also depends on seagrass configuration. Large isolated patches with 800 crabs introduced annually gave a median population threshold equal to that of 400 crabs introduced in very small isolated patches and 200 crabs introduced in continuous habitat. The relative change in populations due to crab introductions was greater in patch configurations with lower abundances. Under a 50\% harvest rate in conjunction with introductions, small close patches remained the best habitat for population persistence because of the larger population abundances and the faster growth rate resulting in relatively quick recovery from harvest, irrespective of the number of crab introductions. The stock of individuals available for introductions is usually limited. Therefore, efficient management may require different levels of introductions for different seascapes. Populations in large isolated patches benefit the most from introductions because the relative increase in abundance is greatest in these patches. If absolute increase is of most interest, then populations in small close patches benefit the most from introductions. However, populations in small close patches start out relatively high in the absence of introductions, so maximizing relative increases may be more appropriate for management.

The way in which seascape structure and harvest interactively affect different life history stages is critical to consider for effective management of fishery species (Botsford et al. 1997, Huxel \& Hastings 1999) and rather than relying on one management strategy to improve population persistence, a combination of approaches may be most effective. For example, in our model, the benefits of reducing fishing pressure outweigh population increases from crab introductions in seascapes with high connectivity (i.e. continuous and small close patches of seagrass). A reduction in harvest allows the population to increase to larger numbers than those in isolated patches. Conversely, introducing a large number of individuals to large or very small isolated patches without reducing harvesting pressure is usually more beneficial than reducing harvest alone. This is because populations in isolated fragments have slow population growth and hence introducing individuals results in faster (albeit artificial) population growth than relying on background population growth alone. In small isolated seagrass patches, introducing 800 individuals and harvesting $50 \%$ of the adult population results in the same median population threshold as for a $30 \%$ harvest rate and $200 \mathrm{crab}$ introductions. The former alternative allows for an almost double harvest rate but it requires great effort to rear and introduce small age 1 crabs annually (Zmora et al. 2005).

Our model incorporates winter and summer survival rates of small age 1 crabs, which were experimentally estimated in different seascapes that existed within a single sub-estuary within Chesapeake Bay. The results of the model therefore address how harvest, habitat loss and fragmentation, and introductions affect population persistence at a local scale. At this scale, the combined effects of harvesting and habitat loss and fragmentation, in addition to the potential of introductions to promote persistence, can be evaluated in isolation of additional and potentially confounding factors that may be present elsewhere in the Bay. To describe the population dynamics of the entire population throughout the bay more accurately, comparable research should be extended to other regions. Additionally, environmental factors not included in our model, such as salinity, water temperature, and depth, may influence blue crab survival (Jensen et al. 2005) and could be incorporated into future models. Future models also may consider a patch-mosaic approach to simulating blue crab habitat, rather than the patchmatrix approach we used in our study. The patchmosaic approach allows for more realism by incorporating a variety of habitat types into seascapes, but requires data on blue crab densities and densitydependent survival within multiple habitat types, as well as rates of movement among habitat types, much of which is not available at present.

One ecological component we did not incorporate into our model is dispersal of individuals across seascapes with combinations of different configurations of fragmentation and habitat loss. Furthermore, models for each seascape assumed that individuals move between seagrass patches without increased mortality, although patch isolation may reduce blue crab movement and survival (Micheli \& Peterson 1999). Adults are known to travel large distances, particularly females that may travel the entire length of Chesapeake Bay to release eggs at the bay mouth (Turner et al. 2003), and may move between patches due to competition and/or lack of resources. Density-dependent dispersal has been documented in newly settled blue crabs (Reyns \& Eggleston 2004), but studies quantifying average dispersal distances are lacking. Incorporating stagedependent dispersal between habitat patches into a metapopulation model could help capture the dynamics over larger spatial scales and possibly identify source and sink populations. 
Efforts to restore seagrass beds are essential for overall ecosystem health, but in order to promote persistence of populations that rely on seagrass as nursery habitat, additional factors, aside from an increase in total acreage, may be important. Habitat configuration is a key component to survival during various life history stages of many invertebrate species. Our model shows that a large area of continuous seagrass habitat is suboptimal for population persistence in the presence of harvest when juvenile survival rates are affected by habitat fragmentation and loss in nonlinear ways. An efficient seagrass restoration strategy should not only increase the amount of vegetation but should also incorporate favorable habitat configurations and structure (Beck et al. 2001). Planting seagrass to reduce the isolation of existing patches will likely promote the survival of younger or smaller life stages and could potentially increase the existing habitat for juveniles, both of which may help increase future population size. Restoration projects therefore should not just focus on the total amount of seagrass restored, but also consider the spatial layout of restoration, and harvest should be considered in the context of the spatial arrangement of seagrass beds.

Human population growth leads to increased environmental degradation due, in part, to an accelerated depletion of resources and unknown synergistic effects of multiple threats (Harte 1996). The harvest of economically valuable species is often targeted as the cause of decline. While this threat can be significant, harvesting can mask the consequences of additional factors because of potential synergies (Ewers \& Didham 2005). The simultaneous evaluation of harvesting, habitat loss, and habitat fragmentation describes how population persistence can be dependent upon various combinations of threats and how management must recognize and address population level responses to these threats.

Acknowledgements. We thank the Willard A. Van Engel Foundation, the Chesapeake Bay Restoration Fund, Sigma Xi Grants-in-Aid-of-Research, the Lerner-Gray Fund for Marine Research, the Commonwealth of Virginia, Virginia Sea Grant, the Chesapeake Bay Stock Assessment Committee, and the Virginia Institute of Marine Science Mini-Grant and Student Research Grant program for support of field and lab work that generated input on blue crab mortality and abundance used in our model. We also thank R. Lipcius, J. E. Duffy, R. Orth, M. Patterson, and D. Eggleston for thoughtful comments on previous publications that generated data to parameterize our model.

\section{LITERATURE CITED}

Akçakaya HR, Root W (1998) RAMAS Metapop: viability analysis for stage-structured metapopulations. Applied Biomathematics, Setauket, NY

Akçakaya HR, Burgman MA, Ginzburg LR (1999) Applied population ecology. Sinauer, New York, NY

BBCAC (Bi-State Blue Crab Advisory Committee) (2005) Blue crab: 2005. Status of the Chesapeake population and its fisheries. Chesapeake Bay Commission, Annapolis, MD

Beck MW, Heck KL Jr, Able KW, Childers DL and others (2001) The identification, conservation, and management of estuarine and marine nurseries for fish and invertebrates. Bioscience 51:633-641

Beverton RJ, Holt SJ (1957) On the dynamics of exploited fish populations. Fish Invest Ser II 19:1-533

> Botsford LW, Castilla JC, Peterson CH (1997) The management of fisheries and marine ecosystems. Science 277: 509-515

Burgman MA, Ferson S, Akçakaya HR (1993) Risk assessment in conservation biology. Chapman and Hall, London

Calkins DG, Becker EF, Pitcher KW (1998) Reducing body size in female stellar sea lions from a declining population in the Gulf of Alaska. Mar Mamm Sci 14:232-244

CBSAC (Chesapeake Bay Stock Assessment Committee) (2005) Chesapeake Bay blue crab advisory report. NOAA, Chesapeake Bay, Annapolis, MD

> Davies KF, Margules CR, Lawrence JF (2004) A synergistic effect puts rare, specialized species at greater risk of extinction. Ecology 85:265-271

- Ewers RM, Didham RK (2005) Confounding factors in the detection of species responses to habitat fragmentation. Biol Rev Camb Philos Soc 81:117-142

Fahrig L (2003) Effects of habitat fragmentation on biodiversity. Annu Rev Ecol Evol Syst 34:487-515

Fogarty MJ, Lipcius RN (2007) Population dynamics and fisheries. In: Kennedy VS, Cronin LE (eds) The blue crab Callinectes sapidus. Maryland Sea Grant College Program, College Park, MD, p 711-756

Harte J (1996) Feedbacks, thresholds and synergies in global change: population as a dynamic factor. Biol Conserv 5: 1069-1083

Hewitt DA, Hoenig JM (2005) Comparison of two approaches for estimating natural mortality based on longevity. Fish Bull 103:433-437

Hovel KA, Lipcius RN (2001) Habitat fragmentation in a seagrass seascape: patch size and complexity control blue crab survival. Ecology 82:1814-1829

Hovel KA, Lipcius RN (2002) Effects of seagrass habitat fragmentation on juvenile blue crab survival and abundance. J Exp Mar Biol Ecol 271:75-98

> Huxel GR, Hastings A (1999) Habitat loss, fragmentation, and restoration. Restor Ecol 7:309-315

> Irlandi EA, Ambrose WG Jr, Orlando BA (1995) Seascape ecology and the marine environment: how spatial configuration of seagrass habitat influences growth and survival of the bay scallop. Oikos 72:307-313

Jensen OP, Seppelt R, Miller TJ, Bauer LJ (2005) Winter distribution of blue crab Callinectes sapidus in Chesapeake Bay: application and cross-validation of a two-stage generalized additive model. Mar Ecol Prog Ser 299:239-255

Marschall EA, Crowder LB (1996) Assessing population responses to multiple anthropogenic effects: a case study with brook trout. Ecol Appl 6:152-167

Mellink E, Ceballos G, Luévano J (2002) Population demise and extinction threat of the Angel de la Guarda deer mouse (Peromyscus guardia). Biol Conserv 108:107-111

> Micheli F, Peterson CH (1999) Estuarine vegetated habitats as corridors for predator movements. Conserv Biol 13: 869-881

Miller TJ (2001) Matrix based modeling of blue crab population dynamics with applications to Chesapeake Bay. Estuaries 24:535-544 
Miller TJ, Martell SJD, Bunnell DB, Davis G and others (2005) Stock assessment of blue crab in Chesapeake Bay. Tech Rep [UMCES]CBL 05-007. Chesapeake Biological Laboratory, Solomons, $\mathrm{MD}$

Moksnes PO, Lipcius RN, Pihl L, van Montfrans J (1997) Cannibal-prey dynamics in young juveniles and postlarvae of the blue crab. J Exp Mar Biol Ecol 215:157-187

Moody KE (1994) Predation on juvenile blue crabs, Callinectes sapidus Rathbun, in lower Chesapeake Bay: patterns, predators and potential impacts. PhD dissertation, College of William and Mary, Williamsburg, VA

Myers N (1996) Two key challenges for biodiversity: discontinuities and synergism. Biodivers Conserv 5:1025-1034

- Myers RA, Hutchings JA, Barrowman NJ (1996) Hypothesis for the decline of cod in the North Atlantic. Mar Ecol Prog Ser 138:293-308

Orth RJ, Moore KA (1983) Chesapeake Bay: an unprecedented decline in submerged aquatic vegetation. Science 222:51-53

Paolisso M (2002) Blue crabs and controversy on the Chesapeake Bay: a cultural model for understanding watermen's reasoning about blue crab management. Hum Organ 61:226-239

Perkins-Visser E, Wolcott TG, Wolcott DL (1996) Nursery roles of seagrass beds: growth of juvenile blue crabs (Callinectes sapidus Rathbun). J Exp Mar Biol Ecol 198:155-173

Pile AJ, Lipcius RN, van Montfrans J, Orth RJ (1996) Densitydependent settler-recruit-juvenile relationships in blue crabs. Ecol Monogr 66:277-300

Prager MH, McConaugha JR, Jones CM, Geer PJ (1990)

Submitted: May 1, 2010; Accepted: December 31, 2010
Fecundity of blue crab, Callinectes sapidus, in Chesapeake Bay: biological, statistical and management considerations. Bull Mar Sci 46:170-179

- Reyns NB, Eggleston DB (2004) Environmentally-controlled, density-dependent secondary dispersal in a local estuarine crab population. Oecologia 140:280-288

Rosenberg AA (2003) Managing to the margins: the overexploitation of fisheries. Front Ecol Environ 1:102-106

Rothschild BJ, Stagg CM, Knotts KS, DiNardo GT, Chai A (1988) Blue crab stock dynamics in Chesapeake Bay. Tech Rep [UMCES] CBL 88-51. Chesapeake Biological Laboratory, Solomons, MD

Rugolo LJ, Knotts KS, Lange AM, Crecco VA (1998) Stock assessment of Chesapeake Bay blue crab (Callinectes sapidus Rathbun). J Shellfish Res 17:493-517

SERC (Smithsonian Environmental Research Center) (2006) Blue crab online resource. Available at http://serc.si.edu/ labs/fish_invert_ecology/bluecrab/reproduction.aspx

Sharov AF, Vølstad JH, Davis GR, Davis BK, Lipcius RN, Montane MM (2003) Abundance and exploitation rate of the blue crab (Callinectes sapidus) in Chesapeake Bay. Bull Mar Sci 72:543-565

> Turner HV, Wolcott DL, Wolcott TG, Hines AH (2003) Postmating behavior, intramolt growth, and onset of migration to Chesapeake Bay spawning grounds by adult female blue crabs, Callinectes sapidus Rathbun. J Exp Mar Biol Ecol 295:107-130

Zmora O, Findiesen A, Stubblefield J, Frenkel V, Zohar Y (2005) Large-scale juvenile production of the blue crab Callinectes sapidus. Aquaculture 244:129-139

Proofs received from author(s): April 4, 2011 